\title{
O QUE É E O QUE NÃO É UM LIVRO: MATERIALIDADES E PROCESSOS EDITORIAIS
}

\author{
QUÉ ES Y QUÉ NO ES UN LIBRO: MATERIALIDADES Y PROCESOS EDITORIALES \\ WHAT IS AND WHAT IS NOT A BOOK: ITS MATERIALITY AND EDITORIAL PROCESSES
}

Ana Elisa Ribeiro*
Centro Federal de Educação Tecnológica de Minas - CEFET-MG, Belo Horizonte, BR

RESUMO: Neste trabalho, propõe-se uma discussão sobre os e-books como produto marcado, não apenas por um enquadramento discursivo ou por um formato, mas também por um processo editorial ao menos parcialmente diferenciado do livro impresso. Além disso, conceitos como o de suporte e o de prática de leitura ajudam a tratar aspectos do modo de ler que estão em evidência quando se fala em livros e em e-books. Os dispositivos de leitura e a experiência do leitor parecem ter papel fundamental na proposição de um processo editorial para livros eletrônicos. Questiona-se aqui se, sendo os processos editoriais de livro impresso e e-book em parte diferenciados, além de terem e propiciarem formato e experiências bastante diferentes, caberia considerar o livro apenas como metáfora do novo produto editorial produzido para ser lido em novos dispositivos. Se os gêneros de texto inscritos são os mesmos, os objetos não o são, cabendo afirmar que o que caracteriza um livro não são, necessariamente, os gêneros que se publicam nele, mas outros elementos de sua caracterização. Embasam este trabalho as discussões de Eco e Carriere (2010), Darnton (2010), Chartier (1998; 2000; 2002) e Procópio (2010) sobre processos de edição. As discussões sobre suporte estão baseadas no trabalho de Távora (2008).

PALAVRAS-CHAVE: processo de edição; livros; e-books; produção editorial.

RESUMEN: En este trabajo, se propone una discusión sobre los e-books como producto marcado, no sólo por un marco discursivo o por un formato, sino también por un proceso editorial al menos parcialmente diferenciado del libro impreso. Además, conceptos como el de soporte y el de práctica de lectura ayudan a tratar aspectos del modo de leer que están en evidencia cuando se habla en libros y en e-books. Los dispositivos de lectura y la experiencia del lector parecen tener un papel fundamental en la proposición de un proceso editorial para libros electrónicos. Se pregunta, aquí, si, siendo los procesos editoriales de libro impreso y e-book en parte diferenciados, además de que esos procesos tienen y propician formato y experiencias bastante diferentes, ¿cabría considerar al libro tan solo como una metáfora del nuevo producto editorial producido para ser leído en nuevos dispositivos? Si los géneros de texto inscritos son los mismos, los objetos no lo son, cabiendo afirmar que lo que caracteriza un libro no son, necesariamente, los géneros que se publican en él, sino otros elementos de su caracterización. La base de este trabajo son las discusiones de Eco y Carriere (2010), Darnton (2010), Chartier (1998; 2000; 2002) y Procópio (2010) sobre procesos de edición. Las discusiones sobre soporte están baseadas en el trabajo de Távora (2008).

PALABRAS-CLAVE: proceso de edición; libros; e-books; producción editorial.

ABSTRACT: In this paper, we propose a discussion on e-books as a marked product, not just as a discursive framework or because its format, but also by an editorial process at least partially distinct from the printed book. Moreover, the concepts of material formats and reading practices help to deal with aspects of reading modes that are in evidence when books and e-books are referred. Devices for reading and reader's experience seem to have a key role in proposing a process for publishing electronic books. It is argued here that, since the editorial processes of the printed book and eBook are partly differentiated, besides offering different size and experience, the book could be considered simply as a metaphor of the new editorial product produced to be read in new devices. If the entered text genres are the same, the objects are not, and thus it can be said that those genres that are published in a book not necessarily characterize it, but other elements of its characterization. The arguments posed here are based on discussions on editing processes (Eco and Carriere, 2010; Darnton, 2010; Chartier, 1998, 2000, 2002; and Procopio, 2010). The concepts of formats are based on Távora (2008).

KEYWORDS: editing process; books; e-books; editorial production.

\section{INTRODUÇÃO}

Os processos editoriais para produção de livros impressos passaram por mudanças importantes nas últimas três décadas. Além disso, a produção de e-books (livro eletrônico) também cresceu, por meio de um processo editorial que gera um produto novo em diversos aspectos, embora sua matriz ainda seja o livro tradicional. Não raro é possível encontrar relatos que descrevem a produção e a edição de livros eletrônicos que em

\footnotetext{
*Email: anadigital@gmail.com.
} 
muito lembram a produção dos impressos, exceto por uma etapa final diferenciada (nos aspectos do produto, da distribuição, do markting e da logística).

A despeito de serem produtos diversos, que ensejam experiências de edição e de leitura também diferenciadas, os e-books ainda não encontraram um espaço definido e definitivo nas redes de edição. Neste trabalho, propõe-se uma discussão sobre os e-books e os livros impressos como produtos marcados não apenas por processos editoriais ao menos parcialmente diferenciados e por definições especializadas que levam em conta diversos aspectos do objeto. Além disso, conceitos como o de suporte $^{1}$ e o de prática de leitura ajudam a tratar aspectos do modo de ler que estão em evidência quando se fala em livros e em ebooks.

O objetivo deste trabalho é discutir o livro em relação ao produto digital que se pode ler em diversos tipos de players (celulares, tablets, computadores etc.) e os critérios que têm sido empregados para se apontar o que seja um livro não como conteúdo, mas como tecnologia. Neste caso, a atenção recai sobre definições institucionais, muitas das quais guiam até mesmo políticas do livro e da publicação ao redor do mundo; ou funcionam como critérios para países inteiros, como é o caso da Unesco (2011).

\section{LIVRO}

Embora pareça corriqueiro lidar com livros, ao ponto de também parecer desnecessário pensar sobre eles, faz-se aqui um convite a um passeio pelas definições de livro que vêm sendo oferecidas por autores e instituições, nos últimos tempos. De tão integrado ao regime cultural em que vivemos, o objeto tornou-se transparente, como ocorre a outros "fatos sociais". Bahloul (2002), em um estudo sociológico sobre o que chama de "pouco leitores" (na França), persegue as definições de livro que emergem de representações que as pessoas constroem socialmente sobre o objeto. Conforme seus resultados, para os franceses que leem pouco, livros são objetos cujas dimensões definidoras são: material, gráfica, de gênero e de autor. Basicamente, a dimensão material diz respeito ao fato de livro ser um objeto impresso, graficamente produzido sob encadernação (e não qualquer uma), prioritariamente ligado a gêneros literários e escrito por autor conhecido e respeitado. Bahloul analisa, com detalhe, essa representação, algo que não faremos aqui, mas seus resultados nos oferecem a oportunidade de comparar as práticas sociais e as definições institucionais de um objeto tão caro à nossa cultura.

Vejamos algumas definições/descrições do objeto livro e passemos, então, a uma breve revisão dos elementos que estão em jogo em seu enquadramento.

A Unesco (Organização das Nações Unidas para a Educação, a Ciência e a Cultura) trabalha com a seguinte descrição do objeto livro: "Publicação não-periódica impressa de no mínimo 49 páginas, além da capa, publicada no país e disponibilizada ao público". Afora os objetos que se enquadrem nessa descrição, um tanto objetiva, os demais serão considerados folhetos.

Faria e Pericão (2008), em seu importante Dicionário do Livro, oferecem, além do verbete "livro", centenas de outros adjetivados (p. ex. livro de horas, livro bifoliado, livro de tabuinhas, entre outros). São doze páginas de verbetes, além da definição geral (com um desenho esquemático das partes formais do livro):

Conjunto de cadernos, manuscritos ou impressos, costurados ordenadamente e formando um bloco • obra, científica ou literária, que forma ou pode formar um volume $\bullet$ cada uma das partes principais em que se dividem os textos dos livros • documento impresso ou não-impresso • transcrição do pensamento

\footnotetext{
${ }^{1}$ Certamente, este é um conceito que merece discussão e aprofundamento, no entanto, não é o objetivo deste trabalho tratar do suporte com mais vagar. Outros autores o fizeram, sendo um deles Távora (2008), aqui citado.

2 "Non-periodic printed publication of at least 49 pages exclusive of the cover pages, published in the country and made available to the public.” Em http://www.uis.unesco.org/ev.php?ID=5096_201\&ID2=DO_TOPIC, acessado em 9 de junho de 2011.
} 
por meio de uma técnica de escrita em qualquer suporte com quaisquer processos de inscrição. O livro supõe um suporte, signos, um processo de inscrição, um significado. Integra-se num processo de criação, reprodução, distribuição, conservação e comunicação. Dirige-se a um leitor, possui uma finalidade: a reflexão, o ensino, o conhecimento, a evasão, a difusão do pensamento e a cultura $\bullet$ segundo a agência portuguesa para o ISBN (International Standard Book Numbering), é toda publicação não-periódica com um mínimo de quarenta e cinco páginas e que esteja sujeita a depósito legal • segundo a ISO (International Standard Organization), é publicação impressa não-periódica, com mais de quarenta e oito páginas, sem incluir as da capa, que constitui uma unidade bibliográfica; monografia • exemplar a partir do qual o editor faz a impressão. (FARIA; PERICÃO, 2008, p. 458-459)

Na mesma obra, o "livro da era digital” aparece com indicação dos verbetes "CD-Rom”, "CD-áudio", “ebook", "livro on-line". O verbete central é "livro eletrônico", que assim descreve o novo objeto: "Aquele em que as palavras ou códigos foram substituídos pelos de uma outra linguagem ou código legível por máquina. Surgiu como alternativa ao livro, texto e documento em suporte papel. Usa-se por oposição ao livro impresso" (FARIA; PERICÃO, 2008, p. 467). E, no verbete "electronic book": "em português, livro eletrônico, versão digital de um livro, artigo ou outro documento • aquilo onde ele se lê, isto é, um computador pessoal, de mesa ou portátil, palm size ou um dedicated eBook reader" (FARIA; PERICÃO, 2008, p. 473).

A Enciclopédia INTERCOM de Comunicação (INTERCOM, 2010, p. 767) traz, no verbete "livro", uma série de abordagens sobre o objeto. Segundo a definição, "A palavra livro é usada para designar tanto uma criação espiritual quanto um objeto, tanto um conteúdo intelectual quanto o seu suporte material”. Albert Labarre é citado para se tecer uma referência aos aspectos do livro que devem ser levados em conta: suporte de escrita, "difusão e conservação de um texto" e portabilidade. Quanto aos formatos, são mencionados o rolo, o códex (cadernos) e o digital ${ }^{3}$. No verbete, Roger Chartier é evocado para se fazer referência ao fato de que as transformações do rolo ao códex não alteraram, em linhas gerais, a estruturação do livro. Isso só ocorreu mais recentemente, com a opção de se ler o "livro" em um display diferente do códex, por exemplo, um tablet.

O Glossário de termos de edição de Queiroz (2008) traz um verbete "livro" que aponta o vocábulo de origem greco-latina e apresenta formatos e materiais com os quais o objeto já foi produzido ao longo da história. O livro moderno, "a partir da invenção da tipografia" (p. 15), é descrito como "uma reunião de folhas dobradas, reunidas em cadernos colados e costurados uns aos outros, em branco, manuscritas ou impressas", com um revestimento que poderia ser encadernado ou brochura.

O Glossário alerta que o livro não deve ser reduzido "ao conceito de registro da palavra escrita, pois, nas sociedades orais, por exemplo, os anciãos são como livros ambulantes, que conservam a memória daquela comunidade" (p. 15). Mais adiante, tratando da atualidade, a obra afirma que "o livro impresso tem sido gradualmente substituído por dispositivos informatizados de leitura, por livros-máquina ou livros eletrônicos interativos que navegam em cabos telefônicos ou ondas hertzianas. Digitalizados e armazenados em CDRoms ou em imensas memórias on-line, ainda sobrevivem paralelamente às suas edições eletrônicas". Queiroz (2008) cita Arlindo Machado, para quem livros são quaisquer dispositivos que gravem, fixem ou memorizem, para uma civilização, o conjunto de seus conhecimentos para a posteridade, incluindo-se descobertas, sistemas de crenças e "voos da imaginação".

A obra A construção do livro, de Araújo (1986), é considerada fundamental para a área de editoração. Nela, o autor aborda diversos aspectos do tratamento editorial e, ao tratar dos formatos, afirma que "Os suportes de escrita que, direta ou indiretamente, influíram na disposição da página impressa, adotaram sempre a forma retangular vertical, i. e., a largura menor que a altura" (ARAÚJO, 1986, p. 415). Nesse aspecto, pode-se pensar numa aproximação física que ainda persiste em relação aos modernos players de toda espécie.

\footnotetext{
${ }^{3}$ É interessante notar que o caso do digital é diferente da relação entre rolo e códex. O digital não é um formato no mesmo sentido que os anteriores. O digital é uma tecnologia, ele está na base da existência de algum formato. Este, por sua vez, no digital, depende do formato do dispositivo que carrega o software.
} 
Segundo Araújo, essa preferência de formato deve-se a uma analogia com as proporções áureas do corpo humano. O papiro, o pergaminho e o papel são discutidos como matéria que daria forma ao livro, com seus limites e suas possibilidades. Quanto aos tamanhos, Araújo (1986) menciona aqueles relativos às dimensões médias do manuscrito no século XV, na Europa (em centímetros): In-plano (28 x 40), In-folio (20 x 28), In$4^{\mathrm{o}}(14 \times 20)$ e In- $8^{\circ}(10 \times 14)$. E, nos impressos, In-plano (entre 32 x 44 e 36 x 48), In-folio (entre 22 x 32 e $24 \times 36), \operatorname{In}-4^{\circ}$ (entre $16 \times 22$ e $\left.18 \times 24\right)$ e In- $8^{\circ}$ (entre $11 \times 16$ e $12 \times 18$ ).

Novos tipos de impressão, criados ao longo dos séculos, trazem novas propostas de formatos-padrão, assim como novas propostas de grids alteram a visualidade do livro. São testadas e propostas proporções e diagramas que se ajustam à página e à experiência da leitura. Araújo (1986, p. 430) fala mesmo em "radicais inovações", em um objeto que "ganhava personalidade" (o impresso, no caso) e em um "esquema construtivo" do livro.

Em outro clássico, A forma do livro, Jan Tschichold (2007) opera uma concepção transparente de design, defendendo que "o designer do livro deve ser um servidor leal e fiel da palavra impressa". Para o autor, deve-se "criar um modo de apresentação cuja forma não ofusque o conteúdo e nem seja indulgente com ele". Importa também que, em meados do século XX, Tschichold ensinava que "o trabalho do artista gráfico deve corresponder às necessidades da época” (p. 31). Na Apresentação ao livro, Robert Bringhurst (2007, p. II) aproxima épocas e tecnologias: "Agora que o chip de silício se juntou à roda, à alavanca e ao plano inclinado, a tipografia é também escrita informatizada, digitalizada; mais complexa do que era, mas não mais profunda; e, talvez, cada vez mais sujeita à moda”.

Richard Hendel (2003) também trata do que chama de "a arte do invisível” quando aborda o design do livro (alusivamente à "arte negra", como é conhecida a impressão), defendendo um lugar distinto para o design deste objeto. E mais: advogando uma espécie de coautoria do designer em relação ao objeto de ler, já que "sua forma física, assim como sua tipografia, também o definem. Cada escolha feita por um designer causa algum efeito sobre o leitor", podendo ser esses efeitos radicais ou sutis.

Haslam (2006) responde à questão "O que é o livro?” com suas aplicações no passado, no presente e no futuro". Para o autor, é "a mais antiga forma de documentação" (p. 6), sendo o que "armazena o conhecimento, as ideias e as crenças do mundo". O objeto de mais de 4 mil anos merece definições, descrições históricas e debates. Segundo Haslam (2006), a palavra livro teria origem no vocábulo bok (saxão e germânico), cuja tradução aproximada seria "tábua/tabuleiro/quadro/prancha para escrever" (a board for writing), enfatizando seu aspecto de suporte. A definição assumida pelo autor, após a análise de várias outras, é assim formulada: "Um recipiente (contêiner) portátil que consiste de uma série de páginas impressas e limitadas que preservam, anunciam, expõem e transmitem conhecimento a um leitor alfabetizado ao longo do tempo e do espaço".

Finalmente, assumindo aspectos do livro como embalagem, navegação e estrutura, a obra $O$ livro $e o$ designer, v. 1, de Fawcett-Tang (2007), afirma as mudanças tecnológicas pelas quais esse objeto vem passando ao longo dos séculos, inclusive na mesma proporção que qualquer outro produto. A aura sacralizada atribuída ao livro, em muitos trabalhos, cede espaço a uma discussão sobre o livro como tecnologia e como interface.

Mais recentemente, Eco e Carriere (2010) e Darnton (2010) publicaram obras no Brasil em que discutem questões do livro, especialmente em relação às tecnologias digitais que os acomodam. Chartier (1998; 2000; 2002), também na esteira dos debates da história cultural, aponta, em diversas obras, a necessidade de que se trate o livro e suas configurações como algo importante para se pensar o leitor, as práticas de leitura e as relações presentes e futuras com os objetos de ler.

\footnotetext{
4. Tentei oferecer uma resposta a essa mesma pergunta no texto "Ler na tela. O que é, hoje, um livro?". Ver Ribeiro (2010b).
} 
Com foco no presente, Procópio (2010) aborda processos de edição e distribuição especialmente voltados aos livros digitais, incluindo-se descrições e defesas dos players e seus modelos, compatibilidades e vantagens.

Os dispositivos de leitura e a experiência do leitor parecem ter papel fundamental na proposição de um processo editorial para livros eletrônicos. Questiona-se aqui se, sendo os processos editoriais de livro impresso e e-book em parte diferenciados, além de terem e propiciarem formato e experiências bastante diferentes, caberia considerar o livro apenas como metáfora do novo produto editorial produzido para ser lido em novos dispositivos. Se os gêneros de texto inscritos são os mesmos, os objetos não o são, cabendo afirmar que o que caracteriza um livro não são, necessariamente, os gêneros que se publicam nele, mas outros elementos de sua caracterização, como se verá adiante.

\section{SUPORTE, PORTADOR, TECNOLOGIA}

Em vários casos, as definições de livro o consideram suporte. Em outros, o material que confere materialidade ao objeto é que é considerado o suporte (papiro, cera, papel, tela (?), etc.). No discurso comum, o livro é tomado como um objeto monolítico, muitas vezes quando se quer atribuir mais valor aos novos dispositivos usados para carregar e expor livros. É importante frisar, no entanto, que o livro é uma tecnologia sócio-historicamente situada, como todas, aliás. Conforme suas configurações, certos gêneros de texto (ou mesmo gêneros no sentido literário) são ali inscritos. Romances, contos, poesia, verbetes, versículos, receitas culinárias, orações, imagens, crônicas, frases, jogos, etc. podem ser inscritos em livros, com usos presumidos bastante diversos, assim como projetos gráficos menos ou mais ajustados à proposição de uma experiência de leitura ou outra.

Marcuschi (2003) propõe uma discussão sobre o que são suportes e elabora sua definição, segundo a qual todo gênero se realiza em um suporte, portanto, o suporte seria condição necessária (mas não suficiente) para a existência de dado gênero. Aponta-se também a interinfluência entre gênero e suporte, sendo que, em medidas diferenciadas, gêneros definem suportes e/ou vice-versa.

O conceito de suporte oferecido por Marcuschi (2003, p. 11) toma-o como um "lócus físico ou virtual”, cujo formato é "específico", "que serve de base ou ambiente de fixação do gênero materializado como texto". Para o autor, o "suporte de um gênero é uma superfície física em formato específico que suporta, fixa e mostra um texto" (MARCUSCHI, 2003, p. 11). Essa definição (entre outras também interessantes) é discutida por Távora (2008), em sua tese de doutorado. Este autor propõe o suporte como uma "entidade mediadora de interação" (TÁVORA, 2008, p. 65), aspecto que considera mais produtivo, "uma vez que, em função da tecnologia criada para interação, determinadas características circunstanciais podem interferir na constituição e mesmo na materialização da textualidade” ${ }^{5}$.

A inter-relação gênero/suporte, que já não parecia facilmente explicável nos impressos e manuscritos, torna-se agora mais complexa com o surgimento de novos ambientes nos quais inscrever ou mostrar textos. Simplificadamente, Teberosky e Colomer (2003) propõem uma diferenciação entre suporte e portador. Estes seriam espaços não exclusivamente dedicados à inscrição de textos, enquanto aqueles teriam o fito exclusivo de fixar ou expor textos. Seguindo essa lógica, livros seriam suportes. Mas o que é um livro, em tempos de telas e dispositivos obsolescentes? Que elementos concorrem para que um livro seja o que é, mesmo se perderem as características físicas que os configuravam até meio século atrás?

\footnotetext{
${ }^{5}$ Elementos da textualidade e da tecnologia nos e-mails são competentemente analisados por Assis (2002; 2002a). Ribeiro (2009) e Ribeiro (2010a) trabalham com a relação entre textos e suportes considerando a "transposição" como um problema editorial. Tavares (2011) apresenta um estudo sobre a "transposição" de textos do gênero reportagem na relação impresso, web e mobile.
} 


\section{OS ELEMENTOS DO LIVRO, POR DEFINIÇÃO}

As definições de livro anteriormente citadas não exaurem as descrições ou as possibilidades do objeto, isso é certo. No entanto, especialistas e instituições consagrados foram selecionados para esta discussão. Com base neles (assumindo a insuficiência disto), apresento uma sumarização dos aspectos mais salientes dessas definições, aspectos esses que se coordenam para enquadrar e caracterizar o objeto livro:

Quadro 1 - Sumário dos elementos levados em consideração em definições de livro

\begin{tabular}{|c|c|c|c|c|c|c|c|c|c|}
\hline & Periodicidade & $\begin{array}{l}\text { Processo de } \\
\text { produção/natureza } \\
\text { tecnológica }\end{array}$ & Volume & $\begin{array}{l}\text { Acesso } \\
\text { público }\end{array}$ & Formato & $\begin{array}{l}\text { Partes } \\
\text { constituintes }\end{array}$ & $\begin{array}{l}\text { Gênero } \\
\text { de } \\
\text { texto }\end{array}$ & Finalidade & Portabilidade \\
\hline UNESCO & $\mathrm{x}$ & $\mathrm{x}$ & $\mathrm{x}$ & $\mathrm{x}$ & $\mathrm{x}$ & $\mathrm{x}$ & & & \\
\hline $\begin{array}{ll}\text { Faria } & \text { e } \\
\text { Pericão } & \end{array}$ & & $x$ & & & $x$ & $x$ & $x$ & $x$ & \\
\hline ISBN & $\mathrm{x}$ & & $\mathrm{x}$ & & & & & & \\
\hline ISO & $\mathrm{x}$ & $\mathrm{x}$ & $\mathrm{x}$ & & & & & & \\
\hline Intercom & & & & & $\mathrm{x}$ & & & $x$ & $\mathrm{x}$ \\
\hline Glossário Ed. & & $\mathrm{x}$ & & & $\mathrm{x}$ & $\mathrm{x}$ & & & \\
\hline Arlindo M & & & & & & & $x$ & $\mathrm{x}$ & \\
\hline Araújo & & $x$ & & & $\mathrm{x}$ & $\mathrm{x}$ & & & \\
\hline Tschichold & & & & & $\mathrm{x}$ & & $\mathrm{x}$ & & \\
\hline Hendel & & & & & $x$ & & & & \\
\hline Haslam & & & & & $\mathrm{x}$ & $\mathrm{x}$ & & $\mathrm{x}$ & $\mathrm{x}$ \\
\hline Fawcett-Tang & & & & & & $\mathrm{x}$ & & & \\
\hline
\end{tabular}

Fonte: Autora.

O quadro permite visualizar alguns elementos mais salientes nas definições de livro feitas pelos especialistas e instituições arrolados para este trabalho. $\mathrm{O}$ formato, seja em relação a tamanho, formas, dimensões ou partes constituintes, é o mais mencionado, estando em quase todos os autores.

Elementos como a periodicidade ou a portabilidade são os menos levados em conta, sendo que a primeira característica só é mencionada por instituições cujo objetivo é padronizar, de alguma maneira, o objeto livro. Para a Unesco ou para reguladores como o ISBN e a ISO, apenas obras não-periódicas são livros, em contraposição a revistas, jornais e outros periódicos.

Apenas a Unesco explicita a relação entre o livro e a publicação. Para os demais autores, não parece haver relação direta entre o objeto e seu acesso, ou talvez essa relação seja pressuposta.

É interessante comentar a natureza tecnológica do objeto como elemento de sua caracterização. Grande parte dos autores explicita essa relação. Para a Unesco (2011), livros são impressos, o que parece excluir outras possibilidades, anteriores ou posteriores. Faria e Pericão (2008) apresentam duas posições a esse respeito: livros são manuscritos ou impressos, quanto à natureza da tecnologia que os concebe, no entanto, as autoras enfatizam a forma de cadernos costurados, algo que os e-books apenas simulam, quando muito. Em outro trecho do verbete, as autoras abrem a definição de livro para "documento impresso ou não impresso", alterando a configuração do leque de objetos que se pode enquadrar aí. Também se define que seja livro a "transcrição" por escrito, em qualquer suporte, com qualquer processo de inscrição. No mesmo dicionário, a definição de e-book considera que esta seja a "versão digital" dos livros, isto é, seu arremedo não-impresso, ou “aquilo em que se lê”, ou seja, o próprio player, seja ele celular, tablet ou outro.

A Intercom assume como livro um objeto produzido a partir da criação intelectual e seu suporte. Outros autores são mais explícitos em admitir que o livro mude de forma ao longo dos séculos, como é o caso de Araújo (1986), mas a maior parte dos especialistas se concentra na função/finalidade do livro, exprimindo-a como a de um objeto capaz de gravar, fixar ou memorizar (Arlindo Machado citado por QUEIROZ, 2008), comunicar, ensinar, refletir, permitir a evasão (FARIA; PERICÃO, 2008), difundir pensamento e cultura e conservar (FARIA; PERICÃO, 2008; INTERCOM, 2010) ou preservar, expor e transmitir ao longo do tempo (presume-se que sem perda), conforme Haslam (2006). Levando ao extremo a finalidade de 
conservação/memória e deslocando esse elemento para o ponto central da definição de livro, Queiroz (2008) considera que os anciãos fossem "livros ambulantes", já que estava com eles (armazenado, memorizado, fixado e pronto para a exposição) o texto a ser ouvido.

O tipo de conteúdo parece ser o que menos interessa para a configuração do objeto livro, o que apenas reforça que outros elementos, como a natureza tecnológica, a finalidade e o formato definam um livro antes de quaisquer outros. O fato de serem dispositivos exclusivos ou não para o texto não está em questão para a maioria dos especialistas, o que descarta ou relativiza muito a importância de distinções como a de portador e suporte, proposta por Teberosky e Colomer (2003).

Marcuschi (2003), interessado na relação suporte/gênero de texto, se aproxima das questões perseguidas pelos especialistas em livros, centralizando elementos como a natureza tecnológica ("lócus físico ou virtual"), o formato (que ele apenas chama de "específico", sem descrevê-lo) e a finalidade ("que serve de base ou ambiente de fixação do gênero materializado como texto", considerando-se esse texto de maneira ampla, talvez não apenas verbal). Segundo Marcuschi (2003), um suporte "suporta, fixa e mostra" um texto, enquanto Távora (2008) enfatiza sua função de "entidade mediadora de interação", algo que não é tratado pelos especialistas do livro, mas sim pelos novos especialistas das interfaces, talvez em consonância com Fawcett-Tang (2007) e, em alguma medida, com os autores que se preocupam com a "transparência" ou com a "opacidade" do design, tais como Tschichold (2007) e Hendel (2003).

Os gêneros textuais, assim como os processos editoriais, sequer são mencionados na maior parte das definições de livro por especialistas da edição, isto é, não se concentra atenção nas relações de interinfluência entre gênero e suporte. O livro, suporte específico, parece enquadrado por aspectos outros, especialmente pela finalidade de tornar perenes as criações textuais do espírito humano, sem deixar de lado questões de formato e tecnologia (manuscrita, impressa ou digital).

\section{CONSIDERAÇÕES FINAIS}

Conforme se pode divisar nesta breve exposição, os critérios ou parâmetros que definem um livro são bastante flexíveis, mesmo entre especialistas da edição. O e-book não é apenas uma "metáfora" do objeto livro impresso, por falta do rebatismo de um novo objeto. Os e-books são livros, propriamente, segundo grande parte das descrições oferecidas pelos autores aqui mencionados. As práticas de leitura propiciadas ou provocadas pelos objetos de ler (rolos, códices ou tablets a bateria) não costumam ser mencionadas quando se descreve o que seja um livro. Verbetes e definições se detêm (por vezes se limitam) nos aspectos formais ou funcionais do dispositivo.

A despeito de o "esquema construtivo" (ARAÚJO, 1986) do e-book ter mudado em relação ao impresso (ao menos quanto à natureza da tecnologia que o materializa), isso não interfere em sua configuração mais geral. Segundo um sumário dos autores aqui elencados, um objeto que serve para (1) conservar a memória da criação intelectual humana, especialmente a textual, cujo formato seja (virtualmente ou não) o de (2) páginas e cadernos organizados e divididos, tendo natureza (3) analógica ou digital, muito provavelmente será um livro. A separação atual entre a materialidade e o inscrito, isto é, hardware e software, não discrimina livro e e-book a ponto de torná-los objetos diferenciados entre si. A despeito de serem tecnologicamente diversos, livros e livros eletrônicos são livros, justo em função de terem a mesma finalidade, assim como de, ao fim e ao cabo, guardarem arquiteturas semelhantes. Mesmo livros eletrônicos para serem lidos em dispositivos dedicados (e-readers, por exemplo) são compostos à maneira dos cadernos costurados que costumavam dar forma e distinguir os livros impressos (e mesmo manuscritos) ${ }^{6}$. Os

\footnotetext{
${ }^{6}$ Em outros trabalhos, exprimi meu conflito com essa indistinção e ela ainda me incomoda. Não oculto minha vontade de definir livro impresso e ebook, sustentando uma diferenciação mais radical entre eles nas práticas editoriais e da leitura propiciadas e provocadas pelos novos objetos. No entanto, precisarei de mais reflexão sobre o assunto.
} 
resultados de Bahloul são diferentes, isto é, o que leitores eventualmente consideram livros são objetos que talvez não se confundam com e-books, já que precisam ser impressos (como algumas instituições consideram), graficamente específicos, mas de autor conhecido e geralmente ligados ao romance e a gêneros literários, aspectos sequer mencionados por qualquer instituição.

Não se pode, portanto, falar em substituição ou em extinção de livros, mas em uma genealogia, que, segundo o raciocínio de Queiroz (2008), remonta ao corpo e à memória humanos como "livro ambulante"? Em suma, pode-se dizer que um livro é um livro, em papel e/ou em pixel's.

\section{REFERÊNCIAS}

ARAÚJO, Emanuel. A construção do livro. Rio de Janeiro: Nova Fronteira; Brasília: Instituto Nacional do Livro, 1986.

ASSIS, Juliana A. Explicitação/implicitação no e-mail e na mensagem em secretária eletrônica: contribuições para o estudo das relações oralidade/escrita. Tese (Doutorado em Linguística) - Universidade Federal de Minas Gerais, Faculdade de Letras, 2002. n. 11, 2002a.

Gêneros textuais, tecnologia e textualização. Scripta, Belo Horizonte: Editora da PUC Minas, v. 6,

BAHLOUL, Joëlle. Lecturas precárias: estudio sociológico sobre los "poco lectores". México: Fondo de Cultura Económica, 2002.

BRINGHURST, Robert. Apresentação. In TSCHICHOLD, Jan. A forma do livro. São Paulo: Ateliê Editorial, 2007.

CHARTIER, Roger. A aventura do livro: do leitor ao navegador. São Paulo: Unesp, 1998.

. Práticas da leitura. São Paulo: Estação Liberdade, 2000.

Os desafios da escrita. São Paulo: Unesp, 2002.

DARNTON, Robert. A questão dos livros. Trad. Daniel Pelizzari. São Paulo: Companhia das Letras, 2010.

ECO, Umberto; CARRIERE, Jean-Claude. Não contem com o fim do livro. Rio de Janeiro: Record, 2010.

FARIA, Maria Isabel; PERICÃO, Maria da Graça. Dicionário do livro: da escrita ao livro eletrônico. São Paulo: EdUsp, 2008.

FAWCETT-TANG, Roger. O livro e o designer I. Trad. Caroline Mariz. São Paulo: Rosari, 2007.

FURTADO, José Afonso. O papel e o pixel: do impresso ao digital - continuidades e transformações.

Florianópolis: Escritório do Livro, 2006.

HASLAM, Andrew. Book design. EUA: Abrams, 2006.

HENDEL, Richard. O design do livro. São Paulo: Ateliê Editorial, 2003.

INTERCOM. Enciclopédia Intercom de Comunicação. 2010. CD-Rom.

MARCUSCHI, L. A. A questão do suporte dos gêneros textuais. DLVC, João Pessoa, v. 1, n. 1, p. 9-40, out. 2003.

PROCÓPIO, Ednei. O livro na era digital. São Paulo: Giz Editorial, 2010.

QUEIROZ, Sonia (Org.). Glossário de termos de edição. Belo Horizonte: Fale/Viva Voz, 2008.

\footnotetext{
${ }^{7}$ Ideia semelhante é apresentada no livro Fahrenheit 451, de Ray Bradbury (publicado em 1953), adaptado para o cinema (com o mesmo nome) por François Truffaut, em 1966.

" Importante fazer referência à obra de José Afonso Furtado, publicada no Brasil, que menciona a "metáfora do livro" em alguns momentos. Ver Furtado (2006).
} 
RIBEIRO, Ana Elisa. Anotações sobre literatura em novas mídias móveis. Ipotesi, Juiz de Fora, v. 14, n. 1, p. 107-114, jan./jul. 2010. Disponível em:

<http://www.ufjf.br/revistaipotesi/files/2009/10/anota\%C3\%A7\%C3\%B5es-sobre-literatura.pdf>.

Ler na tela. O que é, hoje, um livro? In: MARTINS, Aracy A. et al. (Orgs.). Livros छ telas. Belo Horizonte: Editora da UFMG, 2010a.

. Notas sobre o conceito de "transposição" e suas implicações para os estudos da leitura de jornais on-line. Em Questão, Porto Alegre, v. 15, n. 2, p. 15-30, jul./dez. 2009. Disponível em:

<http://revcom2.portcom.intercom.org.br/index.php/revistaemquestao/article/viewFile/5980/5300>.

TAVARES, Maria Luiza Rodrigues R. C. Textos em trânsito, sentidos em trânsito: multimodalidade em textos jornalísticos disponíveis em diferentes suportes. 130 f. Dissertação (Mestrado em Estudos de Linguagens) Centro Federal de Educação Tecnológica de Minas Gerais, 2011.

TÁvORA, Antônio Duarte Fernandes. Construção de um conceito de suporte: a matéria, a forma e a função interativa na atualização dos gêneros textuais. 176 f. Tese (Doutorado em Linguística) - Programa de PósGraduação em Linguística da Universidade Federal do Ceará, Fortaleza, 2008.

TEBEROSKY, Ana; COLOMER, Teresa. Aprender a ler e a escrever: uma proposta construtivista. Trad. Ana Maria Neto Machado. Porto Alegre: Artmed, 2003.

TSCHICHOLD, Jan. A forma do livro. São Paulo: Ateliê Editorial, 2007.

UNESCO. Institute for Statistics. Book. Disponível em:

$<$ http://www.uis.unesco.org/ev.php?ID=5096_201\&ID2=DO_TOPIC $>$. Acessado em: 9 jun. 2011.

Recebido em 01/11/12. Aprovado em 06/01/13. 